\title{
Satisfaction with Sex Life Scale: New Psychometric Evidence in a Portuguese Population
}

\author{
Tomás Caycho-Rodríguez ${ }^{1 \star}$, Lindsey W. Vilca ${ }^{2}$, Felix Neto ${ }^{3}$, Brian Norman Peña-Calero ${ }^{4}$, Berta Schnettler ${ }^{5}$, \\ Cirilo H. Garcia Cadena ${ }^{6}$, Miguel Barboza-Palomino ${ }^{7}$, Joana Neto $^{3}$, Michael White ${ }^{8}$
}

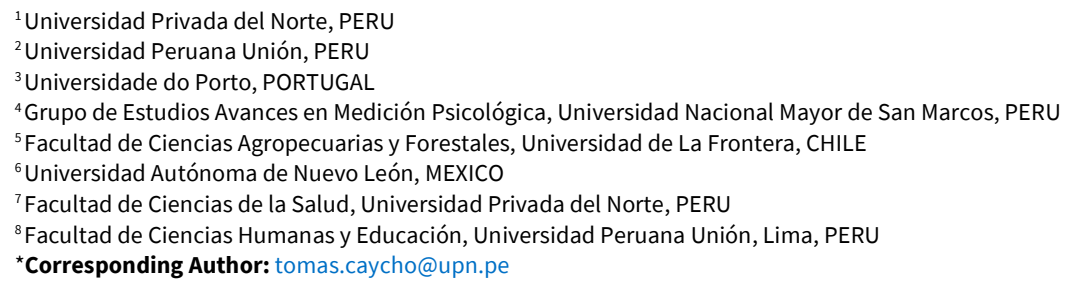

Citation: Caycho-Rodríguez T, Vilca LW, Neto F, Peña-Calero BN, Schnettler B, Garcia Cadena CH, Barboza-Palomino M, Neto J, White M. Satisfaction with Sex Life Scale: New Psychometric Evidence in a Portuguese Population. Electron J Gen Med. 2021;18(6):em331. https://doi.org/10.29333/ejgm/11318

\section{ARTICLE INFO}

Received: 14 Apr. 2021

Accepted: 19 Oct. 2021

\author{
ABSTRACT \\ Introduction: In recent years, greater attention has been paid to research on sexual satisfaction because of its \\ association with general well-being and increased interest in sexual and public health issues.
}

Objectives: The objective of this study was to evaluate the psychometric properties of the Satisfaction with Sex Life Scale (SWSLS).

Methods: 2,154 Portuguese individuals $(M=34.67$ years, $S D=17.18)$ participated. Confirmatory factor analysis (CFA) and item response theory (IRT) were used. Specifically, the internal structure, reliability and factor invariance of the SWSLS were evaluated by sex and age, as well as the characteristics and performance of the items based on the IRT analysis.

Results: The SWSLS Confirmatory Factor Analysis confirmed that a one-dimensional model fit the data well, both for the total sample and for each sex and age group. Furthermore, the SWSLS has adequate reliability for internal consistency. Factor invariance across sex and age was supported by confirmatory multigroup factor analysis. The graduated response model showed a good fit for the one-dimensional model, while the item and test information curves indicated that the SWSLS is more informative to identify high levels of sexual satisfaction.

Conclusion: The SWSLS has adequate psychometric properties to measure general sexual satisfaction in the Portuguese population regardless of age and sex.

Keywords: satisfaction with sex life scale, sexual satisfaction, item response theory, structural equation model, psychometric properties

\section{INTRODUCTION}

In recent years, greater attention has been paid to research on sexual satisfaction because of its association with general well-being and increased interest in sexual and public health issues [1-3]. Sexual satisfaction can be defined as the degree of satisfaction that people have about the sexual aspect of their relationship [4] and the variation of its levels depends on personal variables, factors associated with the couple's relationship, family and sociocultural relations [3]

People with low sexual satisfaction are at greater risk of unsatisfactory relationships and marital problems compared to sexually satisfied individuals [5-7]. Likewise, men who were dissatisfied with their sex lives were more likely to pay for sex [8]. On the other hand, evidence indicates that sexual functioning [9], partner communication [10], marital satisfaction [5], sexual assertiveness [3], social support [11], marital intimacy [12], low religious beliefs [13], and good relationships with children and family are also associated with high levels of sexual satisfaction [14]. Finally, improved sexual satisfaction is associated with a lower rate of heart attacks in men, fewer headaches in men and women, as well as a decrease in premenstrual symptoms and chronic arthritis in women [15].

In relation to sex, some studies indicate that women have greater sexual satisfaction than men [15]; while others report the opposite [14]. However, most research indicates that there is no difference in sexual satisfaction between men and women $[16,17]$. For example, a study comparing sexual satisfaction in university students in Angola, Brazil, Macau, and Portugal reported that there are no significant differences between men and women in these four cultures [18]. Specifically, in Portugal, a study of 1,144 participants between the ages of 20 and 80 
indicated that men and women had no differences in satisfaction with their sex lives, but had sexual satisfaction scores well above average [19]. Recently, research with Portuguese heterosexual college students also reported no significant differences in sexual satisfaction between the two sexes [20]. Another study noted that sexual satisfaction is a similar construct for men and women, characterized by mutual pleasure and that it is a consequence of positive sexual experiences rather than the absence of conflict or dysfunction [21]. However, this study did not include a factor invariance analysis. Likewise, cross-cultural research reported that between $40 \%$ and $60 \%$ of older adults in Denmark, Norway, Belgium, and Portugal reported being sexually satisfied. Portuguese men were one of the groups that reported higher than average sexual satisfaction [22].

Pascoal et al. [8] indicated that, over the years, measures have been developed to evaluate different aspects of sexual satisfaction: 1) Those that emphasize the presence or lack of clinical indicators, such as the Golombok Rust Inventory of Sexual Satisfaction [23]; 2) Those that evaluate individual and relational dimensions, such as the New Sexual Satisfaction Scale [24]; 3) Those that emphasize the evaluation of the interpersonal component of sexuality, such as the Global Measure of Sexual Satisfaction [25]; 4) Those that assess gender-specific characteristics of sexuality such as the Sexual Satisfaction Scale for Women [26]; and 5) Those that assess relational dimensions and overall satisfaction with sexual life, such as the Index of Sexual Satisfaction [27]; or the Satisfaction with Sex Life Scale [28], among others.

The Satisfaction with Sex Life Scale (SWSLS) is a five-item scale that measures satisfaction with one's sex life, defined as the overall assessment a person makes of his or her sex life [28]. This definition allows for a distinction to be made between enjoyment related to sexual activity and general satisfaction with one's sex life, which is a subjective evaluation of one's sex life carried out independently of sexual activity. In this sense, high levels of general satisfaction with their sex lives can be expected regardless of whether or not they have a desire for sexual activity [18]. SWSLS was developed from the Satisfaction with Life Scale (SWLS) [29], where the term "sex life" replaced "life" in all SWLS items. Thus, for example, the item "In most cases, my life is close to my ideal" was replaced by "In most cases, my sex life is close to my ideal". This same procedure has been used to evaluate other satisfaction domains such as love satisfaction [30], migration satisfaction [31], family satisfaction [32-34] and job satisfaction [35,36].

The original study of the SWSLS [28], conducted on a sample of 428 university students in Portugal (246 women and 182 men), reported that the scale presents a single dimension, very good reliability $(\alpha=.92)$ and significant relationships with general satisfaction, love attitudes (Eros, Ludus, Storge, Pragma and Mania), romantic loneliness, commitment or desire to stay in the relationship, frequency of sexual intercourse, as well as positive and negative affect. Likewise, another study, conducted with 1,144 participants between 20 to 80 years old in Portugal [19], indicated that the unidimensional structure of the SWSLS was similar across adulthood (young adults, adults and older adults) in addition to showing very good reliability indices in each age group ( $\alpha=$ .92 for young adults, .86 for adults and .89 for older adults). Similarly, SWSLS scores showed a similar pattern of correlations in all age groups with variables such as Eros, Ludus, Storge and Mania, romantic love, negative affect, positive affect, commitment, sexual desire, and life satisfaction. Finally, a study conducted with 961 university students from four countries (Angola, Brazil, Macao and Portugal) [18], indicated that the unidimensional structure of the SWSLS presents a good fit in each of these cultural groups. Therefore, it is suggested that the SWSLS measures satisfaction with sex life in all four countries. Furthermore, the SWSLS also shows significant correlations with life satisfaction and emotional well-being.

Previous studies have assessed the factor structure of the SWSLS by initially using exploratory factor analysis (EFA) and subsequently confirmatory factor analysis (CFA). However, no exhaustive studies have been carried out that evaluate the psychometric properties of the SWSLS, integrating confirmatory factor analysis (CFA) and Item Response Theory (IRT). While CFA assumes that all examinees have the same measurement accuracy, regardless of their skill levels, in IRT, measurement accuracy is a function of the level of the latent trait. IRT models relate the characteristics of items (difficulty and discrimination) and individuals (latent trait) to the probability of selecting different response options on a scale [37]. Likewise, using IRT, trait scores are obtained at the level of each item, and information is also provided about the reliability of each item according to the different levels of the trait, and it has the advantage that the psychometric properties (such as reliability, item-total correlation, and standard deviation) are independent of the characteristics of the sample [38]. This is the first study to use CFA and IRT procedures for a better understanding of the psychometric evidence of this measurement instrument. In recent years, this type of procedure has become common to evaluate the psychometric properties of instruments that measure indicators of wellbeing $[35,39,40]$.

Another important aspect in relation to the factorial structure of the SWSLS is the evaluation of factor invariance (FI) between different groups [41]. FI is a statistical procedure that provides assurance that a latent construct is measured in the same way over time or between different groups [42]. The absence of Fl implies an inability to make comparisons of latent means between groups [43]. Although there are four levels of invariance (configural, metric, scalar and strict), the literature suggests that the presence of scalar invariance is sufficient to make comparisons between latent means $[44,45]$. To date, there are no studies that have analyzed the FI of the SWSLS among men and women. Additionally, although an earlier study [19] concluded that the factor structure of the SWSLS could be generalized to three different age groups (young adults, adults, and older adults), their methodology lacked a FI analysis. Therefore, it is considered that there are no studies that have tested the invariance of the SWSLS among different age groups with an appropriate method, such as FI.

In this sense, the general objective of the present study was to evaluate the psychometric properties of the SWSLS in a sample of Portuguese individuals, combining CFA and IRT procedures. This is the first study that combines both procedures, which would allow for a better understanding of the psychometric properties of the SWSLS. Specifically, the internal structure, reliability by internal consistency, the FI of SWSLS scores by sex and age, as well as the characteristics and performance of the SWSLS items were evaluated based on IRT analysis. 


\section{METHOD}

\section{Participants}

The participants were 2154 Portuguese individuals from the cities of Porto and Lisbon (1 077 men and 1081 women), whose ages ranged between 18 and 80 years old, with an average age of 34.67 (SD = 17.18). The participants were selected through a convenience sampling. Men $(M=35.58, S D=$ 17.13) had a higher mean age than women $(M=33.75, S D=$ 17.18), and this difference was statistically significant, but it did not have an effect size ( $t=2.478, p=.01, d=.11$ [Cl95\%: .02 .19]). In addition, participants were classified into three groups: early adulthood (18-40 years), middle adulthood (41-65 years), and late adulthood (66-80 years) as proposed by Papalia et al. [46].

\section{Instruments}

Satisfaction with Sex Life Scale (SWSLS) [28]. The SWSLS is made up of five items (e.g., "I am satisfied with my sex life"), each of which has seven Likert-type response options ( $1=$ strongly disagree to $7=$ strongly agree). $\mathrm{A}$ higher SWSLS score expresses a greater satisfaction with one's sex life. The SWSLS items in Portuguese along with their instructions are shown in Appendix 1.

\section{Procedure}

The participants were recruited in the Lisbon and Porto areas by four research assistants. Participants also reported their levels of satisfaction with their sex lives upon completion of the SWSLS, which was administered either collectively or individually. The study was conducted according to the current legal and ethical standards in the country and was in line with the principles of the Declaration of Helsinki. In the collection of information, the anonymity of each participant was ensured, emphasizing that the information provided would be used for strictly academic purposes. The SWSLS was completed in approximately 10 minutes. All respondents voluntarily participated in the study and signed an informed consent, which described the rights of participants, the purpose of the study, and how data would be processed.

\section{Data Analysis}

First, the descriptive analysis of the items was performed (mean [M], standard deviation [SD], asymmetry [g1] and kurtosis [g2]). Second, confirmatory factor analysis (CFA) was performed with the Diagonally Weighted Least Squares with Mean and Variance corrected (WLSMV) estimator due to the ordinal nature of the items [47]. To evaluate model fit, we used the chi-square test $(x 2)$, the Root Mean Square Error of Approximation (RMSEA) index, and the Standardized Root Mean Square Residual (SRMR) index, in which cases values less than .05 indicate good fit, and between .05 and .08 are considered acceptable [48]. In addition, the Comparative Fit Index (CFI) and Tucker-Lewis Index (TLI) were used, with values greater than .95 indicating a good fit and greater than .90 an acceptable fit [49]. The internal consistency of the scale was evaluated with the omega coefficient [50], where a value of $\omega>$ .80 is considered adequate [51]. Also, the Explained Common Variance (ECV) was calculated with the objective of informing to what extent the SWSLS shows evidence of being a onedimensional model $(E C V>.60)[52,53]$.

Regarding the invariance of the SWSLS according to the sex and age of the participants, a sequence of increasingly restrictive hierarchical models was used. First, the configural invariance (reference model) was evaluated, followed by the metric invariance (equality of factor loads), the scalar invariance (equality of factor loads and intercepts) and finally the strict invariance (equality of factor loads, intercepts and residuals). To compare the sequence of models, a formal statistical test was used, using the change in chi-squared $(\Delta x 2)$, where non-significant values ( $p>05)$ suggest invariance between the groups. Secondly, a modeling strategy was employed, using the differences in the CFI $(\triangle C F I)$, where values less than $<.010$ evidence model invariance among the groups [54].

Finally, for Item Response Theory (IRT), a Graduated Response Model was used (GRM) [55], specifically, an extension of the 2-Parameter Logistic Model (2-PLM) for ordered polytomical items [56]. For each item, two types of parameters were estimated, discrimination $(a)$ and difficulty $(b)$. Parameter $a$ determines the slope at which responses to items change as a function of the level in the latent trait, and parameter $b$ determines how much of the latent trait the person requires when answering an item. Since scales have five response categories, there are four difficulty estimates, one per threshold. The estimates for these four thresholds indicate the level of the latent variable at which an individual has a 50\% chance of obtaining a score equal to or greater than a particular response category. Also, the Information Curves for the Items and the Scale (IIC and TIC respectively) were calculated.

The descriptive statistical analyses were performed with the SPSS 22.0 for Windows program. Further analyses were performed with the RStudio environment [57] for R [58]. Specifically, we used the "lavaan" package [59] for CFA, the "semTools" package [60] for factor invariance and the "Itm" package for GRM [61].

\section{RESULTS}

\section{Descriptive Analysis}

Table 1 indicates that item 4 (So far I have gotten the important things I want in my sex life) presents the highest average score in the total sample $(M=5.1)$ and in the different

Table 1. Descriptive analysis of the items in the entire simple and in specific groups

\begin{tabular}{|c|c|c|c|c|c|c|c|c|c|c|c|c|c|c|c|c|c|c|c|c|c|c|c|c|}
\hline \multirow[t]{2}{*}{ Items } & \multicolumn{4}{|c|}{ Men $(n=1075)$} & \multicolumn{4}{|c|}{ Women $(n=1079)$} & \multicolumn{4}{|c|}{$\begin{array}{l}\text { Early adulthood } \\
(n=1515)\end{array}$} & \multicolumn{4}{|c|}{$\begin{array}{l}\text { Middle adulthood } \\
(n=437)\end{array}$} & \multicolumn{4}{|c|}{$\begin{array}{l}\text { Late adulthood } \\
\qquad(n=202)\end{array}$} & \multicolumn{4}{|c|}{$\begin{array}{c}\text { Total } \\
(n=2154)\end{array}$} \\
\hline & $M$ & SD & g1 & g2 & $\mathbf{M}$ & SD & g1 & g2 & $M$ & SD & g1 & g2 & $M$ & SD & g1 & g2 & $M$ & SD & g1 & g2 & $\mathbf{M}$ & SD & g1 & g2 \\
\hline E1 & 4.9 & 1.6 & -.6 & -.2 & 4.9 & 1.5 & -.6 & -.0 & 5.0 & 1.5 & -.7 & .1 & 4.7 & 1.6 & -.5 & -.4 & 4.7 & 1.5 & -.3 & -.3 & 4.9 & 1.5 & -.6 & -.1 \\
\hline E2 & 4.8 & 1.6 & -.5 & -.3 & 4.9 & 1.5 & -.6 & -.1 & 4.9 & 1.5 & -.6 & -.1 & 4.9 & 1.6 & -.6 & -.3 & 4.6 & 1.6 & -.4 & -.5 & 4.8 & 1.6 & -.6 & -.2 \\
\hline E3 & 4.9 & 1.6 & -.6 & -.2 & 5.0 & 1.6 & -.7 & -.1 & 5.0 & 1.6 & -.7 & -.0 & 4.8 & 1.7 & -.5 & -.5 & 4.8 & 1.6 & -.4 & -.4 & 4.9 & 1.6 & -.6 & -.1 \\
\hline E4 & 5.0 & 1.6 & -.7 & -.1 & 5.1 & 1.5 & -.8 & .0 & 5.1 & 1.6 & -.8 & .1 & 5.1 & 1.6 & -.7 & -.1 & 5.0 & 1.5 & -.5 & -.2 & 5.1 & 1.6 & -.7 & -.0 \\
\hline E5 & 4.6 & 1.8 & -.4 & -.8 & 4.8 & 1.7 & -.5 & -.5 & 4.7 & 1.8 & -.5 & -.6 & 4.8 & 1.8 & -.5 & -.6 & 4.5 & 1.8 & -.3 & -.8 & 4.7 & 1.8 & -.5 & -.7 \\
\hline
\end{tabular}

Note. $M=$ Mean; $S D=$ Standard Deviation; $g 1=$ Skewness; $g 2=$ Kurtosis 
Table 2. Adjustment indices for the unidimensional model and for invariance models by sex and age

\begin{tabular}{|c|c|c|c|c|c|c|c|c|c|c|c|c|}
\hline Unidimensional model & $x^{2}$ & df & $p$ & SRMR & TLI & CFI & RMSEA & $\Delta \mathrm{x}^{2}$ & $\Delta$ df & $p$ & $\Delta$ CFI & $\triangle$ RMSEA \\
\hline Total sample & 193.65 & 5 & .000 & .02 & .98 & .99 & .132 & - & - & - & - & - \\
\hline \multicolumn{13}{|l|}{ By sex } \\
\hline Men & 123.47 & 5 & .000 & .02 & .99 & .99 & .149 & - & - & - & - & - \\
\hline Women & 83.52 & 5 & .000 & .02 & .99 & .99 & .121 & - & - & - & - & - \\
\hline Configural & 203.19 & 10 & .000 & .02 & .99 & .99 & .134 & - & - & - & - & - \\
\hline Metric & 168.28 & 14 & .000 & .02 & .99 & .99 & .101 & 2.96 & 4 & .565 & .001 & -.033 \\
\hline Scalar & 133.34 & 38 & .000 & .02 & .99 & .99 & .048 & 24.43 & 24 & .437 & .002 & -.053 \\
\hline Strict & 89.89 & 39 & .000 & .02 & .99 & .99 & .035 & 2.40 & 1 & .121 & .001 & -.013 \\
\hline \multicolumn{13}{|l|}{ By age } \\
\hline Early adulthood (18 to 40 years) & 192.75 & 5 & .000 & .02 & .99 & .99 & .157 & - & - & - & - & - \\
\hline Middle adulthood (41 to 65 years) & 12.53 & 5 & .028 & .01 & .99 & .99 & .059 & - & - & - & - & - \\
\hline Late adulthood (66 to 80 years) & 36.79 & 5 & .000 & .03 & .98 & .97 & .178 & - & - & - & - & - \\
\hline Configural & 186.95 & 15 & .000 & .02 & .99 & .99 & .126 & - & - & - & - & - \\
\hline Metric & 170.75 & 23 & .000 & .02 & .99 & .99 & .095 & 10.98 & 8 & .202 & .001 & -.032 \\
\hline Scalar & 226.78 & 71 & .000 & .02 & .99 & .99 & .055 & 71.32 & 48 & .016 & .000 & -.039 \\
\hline Strict & 177.85 & 73 & .000 & .02 & .99 & .99 & .045 & 4.25 & 2 & .119 & .001 & -.011 \\
\hline
\end{tabular}

Note: $\mathrm{X} 2$ = Chi square; $\mathrm{df}$ = degrees of freedom; SRMR: Standardized Root Mean Square Residual; TLI = Tucker-Lewis Index; CFI = Comparative Fit Index; RMSEA = Root Mean Square Error of Approximation; $\Delta \mathrm{X} 2=$ Differences in Chi square; $\Delta \mathrm{df}=$ Differences in degrees of freedom; $\Delta \mathrm{RMSEA}=$ Change in Root Mean Square Error of Approximation; $\Delta \mathrm{CFI}=$ Change in Comparative Fix Index.

Table 3. Standardized factorial loads for the items and validity of the scale based on sex, age and for the total sample

\begin{tabular}{|c|c|c|c|c|c|c|}
\hline \multirow[t]{2}{*}{ Items } & $\begin{array}{c}\text { Total sample } \\
(n=2154)\end{array}$ & Men $(n=1075)$ & Women ( $n=1079)$ & $\begin{array}{l}\text { Early adulthood } \\
\quad(n=1515)\end{array}$ & $\begin{array}{l}\text { Middle adulthood } \\
\qquad(n=437)\end{array}$ & $\begin{array}{l}\text { Late adulthood } \\
(202)\end{array}$ \\
\hline & $\lambda$ (error) & $\lambda$ (error) & $\lambda$ (error) & $\lambda$ (error) & $\lambda$ (error) & $\lambda$ (error) \\
\hline 1 & $.85(.26)$ & $.84(.28)$ & $.87(.23)$ & $.86(.25)$ & $.84(.29)$ & $.87(.24)$ \\
\hline 2 & $.89(.19)$ & $.91(.16)$ & $.88(.22)$ & $.92(.14)$ & $.82(.31)$ & $.87(.24)$ \\
\hline 3 & $.91(.15)$ & $.92(.14)$ & $.91(.16)$ & $.93(.13)$ & $.90(.18)$ & $.87(.23)$ \\
\hline 4 & $.84(.28)$ & $.84(.28)$ & $.83(.29)$ & $.86(.25)$ & $.78(.38)$ & $.80(.35)$ \\
\hline 5 & $.67(.54)$ & $.67(.54)$ & $.67(.54)$ & $.69(.51)$ & $.58(.65)$ & $.71(.49)$ \\
\hline \multicolumn{7}{|l|}{ Validity } \\
\hline$a$ & .92 & .92 & .92 & .91 & .89 & .91 \\
\hline$\omega$ & .91 & .91 & .91 & .91 & .88 & .90 \\
\hline
\end{tabular}

Note. $\lambda=$ factor loadings

groups: males $(M=5.0)$, females $(M=5.1)$, early adulthood $(M=$ 5.1), intermediate adulthood $(M=5.1)$ and late adulthood $(M=$ 5.0). On the other hand, item 5 (If I could live my sex life over, I would change almost nothing) presents the lowest average score in the total sample $(M=4.7)$ and in the different groups: males $(M=4.6)$, females $(M=4.8)$, early adulthood $(M=4.7)$, intermediate adulthood $(M=4.8)$ and late adulthood $(M=4.5)$. In addition, all items present adequate indices of asymmetry and kurtosis $( \pm 1.5)$ in the total sample and in all specific groups.

\section{Validity based on Internal Structure and Reliability}

Table 2 indicates that, the one-dimensional model presents mostly adequate adjustment rates in the total sample of participants $\left(X^{2}=193.65, \mathrm{df}=5, \mathrm{p}=.000 ; \mathrm{CFI}=.99 ; \mathrm{TLI}=.98\right.$; RMSEA $=.132$; SRMR $=.02)$. Similar results were found in the sample of men $\left(X^{2}=123.47, d f=5, p=.000 ; C F I=.99 ; T L I=.99\right.$; RMSEA $=.149 ;$ SRMR $=.02)$, women $\left(X^{2}=83.52, d f=5, p=.000 ; C F I\right.$ $=.99 ; \mathrm{TLI}=.99 ; \mathrm{RMSEA}=.121 ; \mathrm{SRMR}=.02)$, early adults $\left(X^{2}=192.75, \mathrm{df}=5, \mathrm{p}=.000 ; \mathrm{CFI}=.99 ; \mathrm{TLI}=.99 ; \mathrm{RMSEA}=.157 ; \mathrm{SRMR}\right.$ $=.02)$, middle adults $\left(X^{2}=12.53, \mathrm{df}=5, \mathrm{p}=.028 ; \mathrm{CFI}=.99 ; \mathrm{TLI}=.99\right.$; RMSEA = .059; SRMR $=.01)$ and late adult $\left(X^{2}=36.79, \mathrm{df}=5\right.$, $\mathrm{p}=.000 ; \mathrm{CFI}=.97 ; \mathrm{TLI}=.98 ; \mathrm{RMSEA}=.178 ; \mathrm{SRMR}=.03)$.

Furthermore, the factorial loads of each of the items are high and statistically significant in the total sample and in the specific groups (see Table 3). Likewise, the Explained Common Variance provides evidence of the existence of a onedimensional model in the total sample $(E C V=.71)$ and in the specific groups: men $(E C V=.72)$, women $(E C V=.71)$, early adulthood $(E C V=.69)$, middle adulthood $(E C V=.63)$ and late adulthood $(E C V=.69)$. Finally, the SWSLS presents adequate reliability indices in the total sample $(\omega=.91)$ and in the specific groups: men $(\omega=.91)$, women $(\omega=.91)$, early adulthood $(\omega=$ $.91)$, middle adulthood $(\omega=.88)$, late adulthood $(\omega=.90)$.

\section{Factorial Invariance by Sex and Age}

Because the undimentional model fits well in each of the sex and age groups separately, a set of models was tested for invariance. Table 2 reports the goodness-of-fit indices for the sequence of models and their differences from the baseline (configural) model. The factor structure of the SWSLS shows evidence of being strictly invariant for the groups of males and females, according to the sequence of invariance models proposed (see Table 2): metric $(\Delta C F I=.001)$, scalar $(\Delta C F I=.002)$ and strict $(\triangle \mathrm{CFI}=.001)$ invariance. Similarly, in the early, middle and late adult groups, the scale also showed evidence of being strictly invariant, in the invariance models proposed: metric $(\triangle \mathrm{CFI}=.001)$, scalar $(\Delta \mathrm{CFI}=.000)$ and strict invariance $(\triangle \mathrm{CFI}=.001)$.

\section{Item Response Theory Model: Graduated Response Model (GRM)}

The results found in the Confirmatory Factor Analysis (CFA) show evidence to affirm the existence of unidimensionality and consequently the local independence of the items. In Table 4, it can be seen that all item discrimination parameters are above the value of 1 , generally considered to be good discrimination [56]. With respect to the difficulty parameters, all the threshold estimators increased monotonically, as 
Table 4. Discrimination parameters and difficulty for each item in the scale

\begin{tabular}{|c|c|c|c|c|c|c|c|}
\hline Item & $\mathbf{a}$ & $b_{1}$ & $\mathbf{b}_{2}$ & $b_{3}$ & $\mathbf{b}_{4}$ & $b_{5}$ & $\mathbf{b}_{6}$ \\
\hline $\mathrm{S} 1$ & 3.45 & -1.93 & -1.44 & -1.00 & -.33 & .29 & 1.14 \\
\hline S2 & 3.84 & -1.82 & -1.34 & -.91 & .28 & .32 & 1.11 \\
\hline S3 & 4.16 & -1.77 & -1.34 & -.93 & -.35 & .23 & .98 \\
\hline S4 & 3.04 & -1.95 & -1.50 & -1.09 & -.42 & .15 & .99 \\
\hline S5 & 1.70 & -2.03 & -1.46 & -.95 & -.24 & .39 & 1.20 \\
\hline
\end{tabular}

Note. $a=$ discrimination parameters; $b=$ difficulty parameters

\section{Test Information Function}

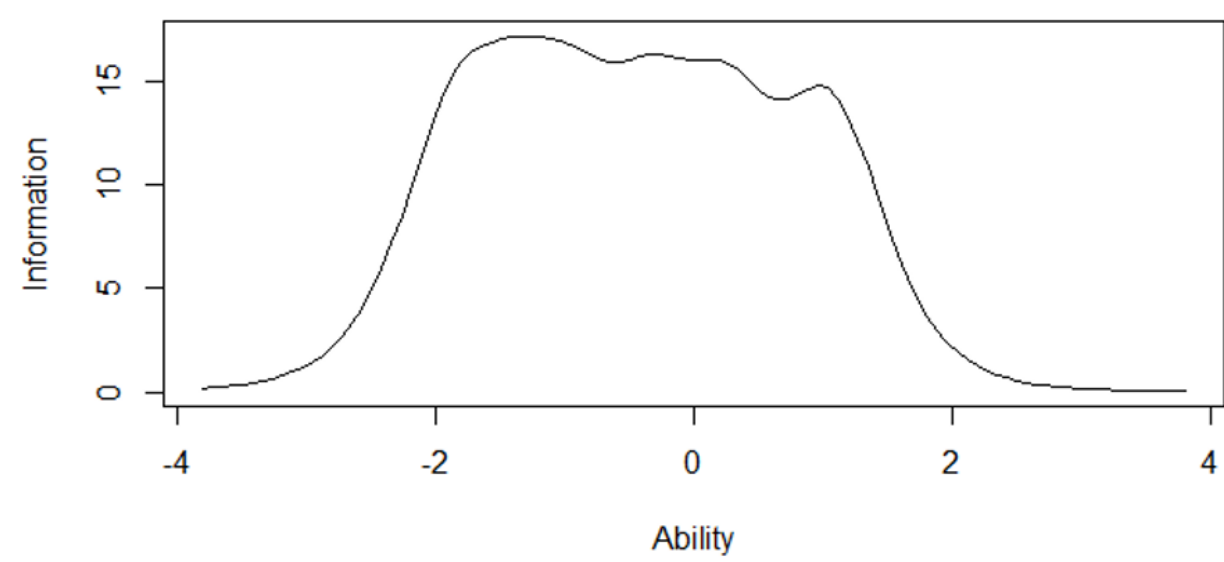

Tests Information Curves (TIC)

\section{Item Information Curves}

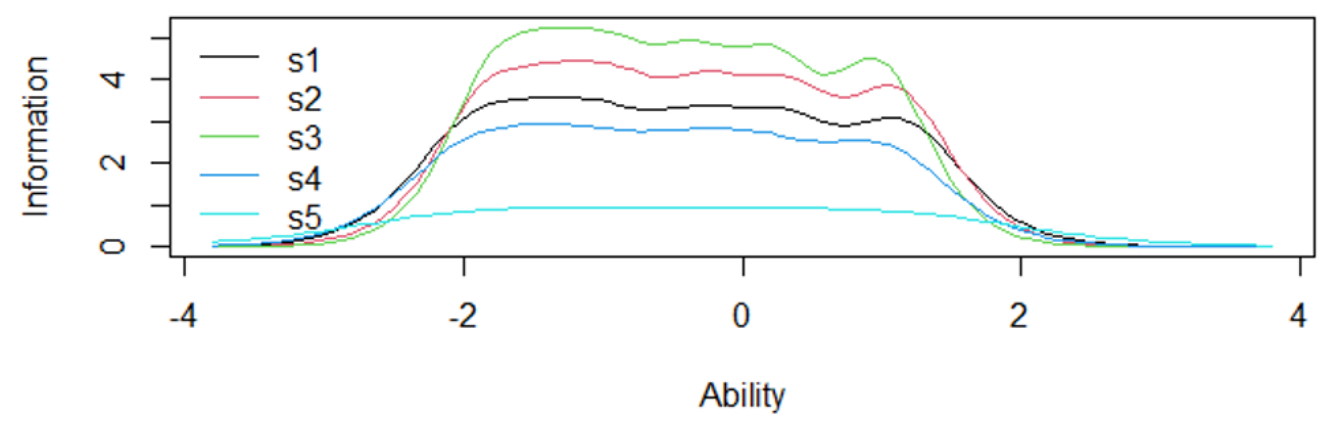

Item Information Curves (IIC)

Figure 1. Item and test information curves for the scale

expected. That is, a greater presence of the latent trait is required to answer the higher response categories.

The IICS and TIC are shown in Figure 1. Items 3, 2, 1 and 4 are the most accurate on the scale for assessing the latent trait. In addition, the TIC shows that the items as a whole allow for more precise collection of information (reliability) within the skill (trait) ranges of -2.0 to 1.5 logits.

\section{DISCUSSION}

In the present study, the SWSLS [28] was administered to a sample of 2154 Portuguese men and women from different age groups, with the aim of examining its psychometric properties, factor structure, reliability, item characteristics and FI across age and sex. In summary, the SWSLS was demonstrated to be a reliable measure with evidence of validity to assess sexual satisfaction in a Portuguese population of both sexes, as well as of different age groups.
The CFA findings provide further evidence which confirms the one-dimensional structure of the SWSLS $[18,19]$. However, the RMSEA values were above the recommended cut-off points for this type of study. In this study, the RMSEA was not used to decide the fit because of its low performance in models with very few degrees of freedom, as in this case and how it depends on the model's $X 2$ value $[62,63]$. In this sense, the high values of the RMSEA in the total sample and all subgroups can be understood based on the above.

All SWSLS items had high factor loads (the lowest was .58 in the middle adult group) and adequate levels of reliability in the different sex and age groups (all coefficients were greater than .88). Item five ("If I could live my sex life again, I would change almost nothing") is the one with the lowest factor load value. This result is also observed in previous studies with the SWSLS $[18,19]$ as well as with the SWLS from which it is derived $[32,64,65]$. This finding is explained by the fact that item five presents an orientation towards the past and not towards the present like the other four items [63]. In addition, previous studies reported that the SWLS correlates more strongly with 
the present $(r=.92)$ compared to past $(r=.72)$ and future $(r=$ .59) time. However, it is important to consider that the life satisfaction construct and its domains seem to be influenced by temporality [66], as demonstrated by the creation of a temporal version of the SWLS [65].

The results provide additional findings about the $\mathrm{FI}$ of the SWSLS. This study reported a strict invariance in all groups by sex and age in a sample of more than two thousand Portuguese participants. In this sense, both the factor structure of the SWSLS and the quality of its items do not vary according to the sex and age of the participant, which indicates that satisfaction with sex life as measured by the SWSLS has the same meaning throughout a person's lifetime, as well as for both men and women. First, no differences were observed in factor loads (metric invariance). This indicates that the latent variable (satisfaction with sex life) is associated with the items in the same way for the different sexes and age groups in the total sample. Second, constraints that match intercepts (scalar invariance) and residues (strict invariance) showed a similar adjustment and no statistically significant difference based on the $\times 2$ test. However, studies with large samples (like this case) can report high $X 2$ values and therefore an increased risk of rejecting suitable models. On the other hand, the CFI index varied slightly $(\triangle \mathrm{CFI})$ by adding restrictions to the reference model (matching intercepts and residues). This indicates that group means and correlations with the latent variable are comparable according to sex and age. These findings on FI for the SWSLS are the first reported in the international literature. Taken together, the CFA and FI results indicate that satisfaction with sex life can be expressed in a single underlying dimension in both men and women and throughout their adult life.

The analysis of the parameters (discrimination and difficulty) through the IRT-GRM model adds relevant precisions to the operation of the items. Item 3 "I am satisfied with my sex life" has the highest value in the estimated discrimination parameter. A high value for this parameter indicates when an item can generate differentiated responses (from strongly disagreeing to strongly agreeing) in people with different levels of traits in the construct of interest (satisfaction with one's sex life). In this sense, item 3 is shown as the one that can collect the greatest amount of information (differentiated responses) from the respondents, and at the same time, as the item that contributes the most to the soundness of the SWSLS. The rest of the items maintain in a similar way an adequate value in the discrimination parameter, which shows that the necessary difficulty to respond to the items is always in an ascending scale. This is an ideal scenario in a measurement instrument.

The TIC and the IICs provide further support for the items and the instrument as a whole. Items 3, 2, 1, and 4 (in that order) are those that extract the most information from people with a trait level between -2 and 1.5 logits. This range of ability (trait) corresponds to an average measurement of the level of sexual satisfaction that is generally attributed to the average person or general population [67]. In other words, the SWSLS is able to measure very accurately (reliability) average levels of sexual satisfaction in the general population that is over 18 years of age. The SWSLS also allows for the identification of extremes in the level of its trait (low or high sexual satisfaction) with the limitation of not adequately differentiating individuals who fall into these categories. For example, a person with extreme impairment in sexual satisfaction might have a similar rating as someone with average impairment in sexual satisfaction. The same would happen at the other extreme, where someone with extreme sexual satisfaction might get a similar or equal rating as someone with high sexual satisfaction. In this way, the SWSLS is a robust and reliable measurement instrument that can be used for general purpose research purposes and/or as a rapid assessment tool for sexual satisfaction. To further explore extreme groups in more detail, it should be complemented with an additional scale designed specifically for that purpose.

This study is not free of limitations. First, the participants were only from the cities of Porto and Lisbon, but not from other regions of Portugal. Furthermore, they were selected from a non-probabilistic sample for convenience. In this sense, the results cannot be generalized to other contexts. Second, test-retest reliability was not examined. Third, a crosssectional research design was used. Therefore, future studies should use longitudinal designs which would enable a better understanding of satisfaction with sex life throughout the life cycle. Fourth, the SWSLS has so far only been applied in Portuguese, so future studies should validate it in other languages such as English or Spanish. Fifth, since this is a selfreport instrument, it could have responses bias. Future studies should use other different measures, such as the sexual partner's evaluation, if possible. In sixth place, the convergent and discriminant validity of the SWLSS should be evaluated [68]. Finally, another limitation relates to the exclusive use of a one-dimensional measure of satisfaction with one's sex life. Sexual satisfaction has been understood as a multidimensional construct [69], so these different dimensions may not be equally invariant for the sex and age groups reported.

As far as we know, this study is the first to validate the SWSLS, in a large sample of Portuguese adults, using the CFA and IRT models. In conclusion, the SWSLS has adequate psychometric properties to measure satisfaction with sex life in Portuguese adults. One of the main strengths of the study is the large number of participants. In addition, among the main contributions, the findings allow us to replicate the unidimensional structure in a sample of people between 18 and 80 years old and thus, based on IRT procedures, suggest that the SWSLS can measure much more accurately the average levels of sexual satisfaction in the general population over 18 years of age. Furthermore, the $\mathrm{FI}$ results allow for comparisons of overall sexual satisfaction between men and women, as well as between different age groups, without the presence of misinterpretation or bias. That is, it is possible to have a certain degree of certainty that the differences found when comparing satisfaction with sexual life (measured with the SWSLS) between different sex and age groups will be the product of real differences in the construct and not merely of different responses to the SWSLS items [43]. Additionally, these results are added to the body of knowledge about the SWSLS in order to consider it a brief measure of overall sexual satisfaction regardless of whether or not one is sexually active. Likewise, the results of the FI become even more necessary if the results serve as a basis for diagnostic processes, treatment, development of epidemiological studies or for the formulation of public policies in health or education [43]. However, more psychometric studies are needed in various regions of Portugal and other countries, such as Latin America where studies with the scale do not yet exist.

Author contributions: All authors have sufficiently contributed to the study, and agreed with the results and conclusions.

Funding: No funding source is reported for this study.

Declaration of interest: No conflict of interest is declared by authors. 


\section{REFERENCES}

1. Mark KP, Herbenick D, Fortenberry JD, Sanders S, Reece M. A psychometric comparison of three scales and a singleitem measure to assess sexual satisfaction. J Sex Res 2014;51(2):159-69. https://doi.org/10.1080/00224499.2013. 816261 PMid:24112135

2. Noruzi S, Maarefvand M, Khankeh H, Eghlima M. Sexual satisfaction studies in Iran, a systematic review. Women Health Bull 2019;6(4):1-7. https://doi.org/10.30476/ WHB.2019.45878

3. Sanchez-Fuentes M, Salinas JM, Sierra JC. Use of an ecological model to study sexual satisfaction in a heterosexual Spanish sample. Arch Sex Behav 2016; 45(8):1973-88. https://doi.org/10.1007/s10508-016-0703-9 PMid:26969318

4. Sprecher S, Cate RM. Sexual satisfaction and sexual expression as predictors of relationship satisfaction and stability. In Handbook of sexuality in close relationships; JH Harvey, A Wenzel, S Sprecher, Eds.; Mahwah, NJ: Erlbaum, 2004:235-56.

5. Cao H, Zhou N, Fine MA, Li X, Fang X. Sexual satisfaction and marital satisfaction during the early years of Chinese marriage: A three-wave, cross-lagged, actor-partner interdependence model. J Sex Res 2019;56(3):391-407. https://doi.org/10.1080/00224499.2018.1463503 PMid:29746180

6. Quinn-Nilas C. Relationship and sexual satisfaction: A developmental perspective on bidirectionality. J Soc Pers Relat 2020;37(2):624-46. https://doi.org/10.1177/02654075 19876018

7. Vowels LM, Mark KP. Relationship and sexual satisfaction: A longitudinal actor-partner interdependence model approach. Sex Relation Ther 2020;35(1):46-59. https://doi.org/10.1080/14681994.2018.1441991

8. Deogan C, Jacobsson E, Mannheimer L, Björkenstam C. Are men who buy sex different from men who do not? Exploring sex life characteristics based on a randomized population survey in Sweden. Arch Sex Behav, 2020:1-7. https://doi.org/10.1007/s10508-020-01843-3 PMid:33354757 PMCid:PMC8275502

9. Pascoal PM, Narciso IDSB, Pereira NM, Ferreira AS. Validation process of the Global Measure of Sexual Satisfaction in three samples of the portuguese population. Psicol Reflex Crit 2013;26(4):691-700. https://doi.org/10.1590/S0102-79722013000400009

10. Blunt-Vinti H, Jozkowski KN, Hunt M. Show or tell? Does verbal and/or nonverbal sexual communication matter for sexual satisfaction? J Sex Marital Ther 2019;45(3):206-17. https://doi.org/10.1080/0092623X.2018.1501446 PMid:30040593

11. Khodabakhshi-Koolaee A, MirAfzal NS. Relationship between humor and social support with sex satisfaction in elderly married women. J Gerontol 2017;2(1):1-10. https://doi.org/10.29252/joge.2.1.1

12. Ariapooran S, Raziani S. Sexual satisfaction, marital intimacy, and depression in married Iranian nurses with and without symptoms of secondary traumatic stress. Psychol Rep 2019;122(3):809-25. https://doi.org/10.1177/ 0033294118776927 PMid:29771198
13. Higgins JA, Trussell J, Moore NB, Davidson JK. Virginity lost, satisfaction gained? Physiological and psychological sexual satisfaction at heterosexual debut. J Sex Res 2010; 47(4):384-94. https://doi.org/10.1080/00224491003774792 PMid:20401787 PMCid:PMC3572537

14. Ji J, Norling AM. Sexual satisfaction of married urban Chinese. J Dev Soc 2004;20(1-2):21-38. https://doi.org/10.1177/0169796X04048301

15. McNulty JK, Fisher TD. Gender differences in response to sexual expectancies and changes in sexual frequency: A short-term longitudinal study of sexual satisfaction in newly married couples. Arch Sex Behav 2008;37(2):229-40. https://doi.org/10.1007/s10508-007-9176-1 PMid:17641964

16. McClelland SI. Who is the "self" in self reports of sexual satisfaction? Research and policy implications. Sex Res Social Policy 2011;8(4):304. https://doi.org/10.1007/ s13178-011-0067-9

17. Santos-Iglesias P, Sierra Freire JC, García M, Martínez A, Sánchez A, Tapia MI. Índice de Satisfacción Sexual (ISS): un estudio sobre su fiabilidad y validez. J Psicol Ter Psicol 2009;9(2):259-23.

18. Neto $F$, da Conceição Pinto M. A cross-cultural investigation of satisfaction with sex life among emerging adults. Soc Indic Res 2015;120(2):545-57. https://doi.org/10.1007/ s11205-014-0604-Z

19. Neto $F$, da Conceição Pinto $M$. The satisfaction with sex life across the adult life span. Soc Indic Res 2013;114(3):767-84. https://doi.org/10.1007/s11205-012-0181-y

20. Peixoto MM, Amarelo-Pires I, Pimentel Biscaia MS, Machado PP. Sexual self-esteem, sexual functioning and sexual satisfaction in Portuguese heterosexual university students. Psychol Sex 2018;9(4):305-16. https://doi.org/ 10.1080/19419899.2018.1491413

21. Pascoal P M, Narciso IDSB, Pereira NM. What is sexual satisfaction? Thematic analysis of lay people's definitions. J Sex Res 2014;51(1):22-30. https://doi.org/10.1080/ 00224499.2013.815149 PMid:24070214

22. Træen B, Štulhofer A, Janssen E, Carvalheira AA, Hald GM, Lange T, Graham C. Sexual activity and sexual satisfaction among older adults in four European countries. Arch Sex Behav 2019;48(3):815-29. https://doi.org/10.1007/s10508018-1256-x PMid:29987546

23. Rust J, Golombok S. Golombok Rust Inventory of Sexual Satisfaction. Windsor: NFER-Nelson Publishing Company 1986.

24. Štulhofer A, Buško V, Brouillard P. Development and bicultural validation of the new sexual satisfaction scale. $J$ Sex Res 2010;47(4):257-68. https://doi.org/10.1080/ 00224490903100561 PMid:19629836

25. Lawrance K-A, Byers ES. Sexual satisfaction in long-term heterosexual relationships: The interpersonal exchange model of sexual satisfaction. Pers Relatsh 1995;2(4):267-85. https://doi.org/10.1111/j.1475-6811.1995.tb00092.x

26. Meston C, Trapnell P. Outcomes assessment: Development and validation of a five - factor sexual satisfaction and distress scale for women: The Sexual Satisfaction Scale for Women (SSS - W). J Sex Med 2005;2(1):66-81. https://doi.org/10.1111/j.1743-6109.2005.20107.x PMid:16422909 PMCid:PMC2859306

27. Hudson WW, Harrison DF, Crosscup PC. A short-form scale to measure sexual discord women. J Sex Res 1981; 17(2):157-74. https://doi.org/10.1080/00224498109551110 
28. Neto F. The satisfaction with sex life scale. Meas Eval Couns Dev 2012;45(1):18-31. https://doi.org/10.1177/ 0748175611422898

29. Diener ER, Emmons R, Larsen R, Griffin S. The Satisfaction with Life Scale. J Pers Assess 1985;49:71-5. https://doi.org/ 10.1207/s15327752jpa4901_13 PMid:16367493

30. Neto F. The Satisfaction with Love Life Scale. Meas Eval Couns Dev 2005;38:2-13. https://doi.org/10.1080/ 07481756.2005.11909765

31. Neto F, Fonseca AC. The Satisfaction with Migration Life Scale. Int J Intercult Relat 2016;54:47-54. https://doi.org/10.1016/j.ijintrel.2016.07.004

32. Caycho-Rodríguez T, Ventura-León J, Barboza-Palomino M, Reyes-Bossio M, et al. Validez e invarianza factorial de una medida breve de Satisfacción con la Vida Familiar. Univ Psychologica 2018;17(5):1-17. https://doi.org/10.11144/ Javeriana.upsy17-5.vifm

33. da Costa M P, Neto F. Psychometric evaluation of the Portuguese satisfaction with family life scale. Meas Instrum Soc Sci 2019;1(1):7. https://doi.org/10.1186/s42409-0190009-5

34. Caycho-Rodríguez T, Neto F, Reyes-Bossio M, Vilca LW, García Cadena CH, Pinto da Costa M, ... White M. Factorial invariance of Satisfaction with Family Life Scale in adolescents from Peru and Portugal. J Gen Psychol 2020;122. https://doi.org/10.1080/00221309.2020.1867496

35. Caycho-Rodríguez T, Neto J, Tomás JM, Valencia PD, Ventura-León J, Neto F, ... Vilca LW. Psychometric properties of the Satisfaction with Job Life Scale in Portuguese workers: A systematic study based on the IRT and CFA modeling. Heliyon 2020;6(6):e03881. https://doi.org/10.1016/j.heliyon.2020.e03881 PMid:32514482 PMCid:PMC7267718

36. Neto F, Fonseca AC. The Satisfaction with Job Life Scale among Immigrants. Psychol Stud 2018;63(3):209-18. https://doi.org/10.1007/s12646-018-0449-7

37. Hambleton RK, Robin F, Xing D. Item response models for the analysis of educational and psychological test data. In Handbook of applied multivariate statistics and mathematical modeling; HEA Tinsley, SD Brown Eds.; San Diego, CA: Academic Press 2000:553-585.

38. Muñiz J. Introducción a la psicometría. Teoría clásica y TRI. Madrid: Ediciones Pirámide; 2018.

39. Schotanus-Dijkstra M, Peter M, Drossaert $\mathrm{CH}$, Pieterse ME, Bolier L, Walburg, JA, Bohlmeijer ET. Validation of the Flourishing Scale in a sample of people with suboptimal levels of mental well-being. BMC psychol 2016;4(1):1-10. https://doi.org/10.1186/s40359-016-0116-5 PMid:26988345 PMCid:PMC4794907

40. Bourion-Bédès $S$, Schwan R, Epstein J, Laprevote V, Bédès A, Bonnet JL, Baumann C. Combination of classical test theory (CTT) and item response theory (IRT) analysis to study the psychometric properties of the French version of the Quality of Life Enjoyment and Satisfaction Questionnaire-Short Form (Q-LES-Q-SF). Qual Life Res 2015;24(2):287-93. https://doi.org/10.1007/s11136-0140772-y PMid:25113237

41. Dong Y, Dumas D. Are personality measures valid for different populations? A systematic review of measurement invariance across cultures, gender, and age. Personal Individ Differ 2020;160:109956. https://doi.org/10.1016/j.paid.2020.109956
42. Putnick DL, Bornstein MH. Measurement invariance conventions and reporting: The state of the art and future directions for psychological research. Dev Rev 2016;41:7190. https://doi.org/10.1016/j.dr.2016.06.004 PMid: 27942093 PMCid:PMC5145197

43. Caycho T. Importancia del análisis de invarianza factorial en estudios comparativos en Ciencias de la Salud. Rev Cuba Educ Medica Super 2017;31(2):1-3. Available at: https://www.medigraphic.com/pdfs/educacion/cem2017/cem172d.pdf

44. Davidov E, Meuleman B, Cieciuch J, Schmidt P, Billiet J. Measurement equivalence in cross-national research. Annu Rev Sociol 2014;40:55-75. https://doi.org/10.1146/annurevsoc-071913-043137

45. Van de Schoot R, Lugtig P, Hox J. A checklist for testing measurement invariance. Eur J Dev Psychol 2012;9(4):486492. https://doi.org/10.1080/17405629.2012.686740

46. Papalia DE, Feldman RD, Martorell G, Berber Morán E, Vázquez Herrera M. Desarrollo humano (12a ed.). México, D. F.: McGraw-Hill Interamericana; 2012.

47. Brown TA. Confirmatory Factor Analysis for Applied Research, Second Edition. Guilford Publications; 2015.

48. Kline RB. Principles and Practice of Structural Equation Modeling (4th ed.). The Guilford Press; 2015.

49. Schumacker RE, Lomax RG. A Beginner's Guide to Structural Equation Modeling: Fourth Edition (4th ed.). Routledge; 2015. https://doi.org/10.4324/9781315749105

50. McDonald RP. Test Theory: A Unified Treatment. Taylor \& Francis, 1999.

51. Raykov T, Hancock GR. Examining change in maximal reliability for multiple-component measuring instruments. $\mathrm{Br} J$ Math Stat Psychol 2005;58(1):65-82. https://doi.org/10.1348/000711005X38753 PMid:15969840

52. Reise SP, Scheines R, Widaman KF, Haviland MG. Multidimensionality and structural coefficient bias in structural equation modeling: A bifactor perspective. Educ Psychol Meas 2013;73(1):5-26. https://doi.org/10.1177/ 0013164412449831

53. Rodriguez A, Reise SP, Haviland MG. Evaluating bifactor models: Calculating and interpreting statistical indices. Psychol Methods 2016;21(2):137-50. https://doi.org/ 10.1037/met0000045 PMid:26523435

54. Chen FF. Sensitivity of goodness of fit indexes to lack of measurement invariance. Struct Equ Modeling 2007;14(3): 464-504. https://doi.org/10.1080/10705510701301834

55. Samejima F. Graded response model. In Handbook of modern Item Response Theory; WJ Van der Linden, RK Hambleton (Eds.); New York, NY: Springer 1997:85-100. https://doi.org/10.1007/978-1-4757-2691-6_5

56. Hambleton RK, van der Linden WJ, Wells CS. IRT models for the analysis of polytomously scored data: Brief and selected history of model building advances. In Handbook of polytomous item response models; ML Nering, R Ostini (Eds.); New York, NY: Routledge 2010:21-42.

57. RStudio Team. RStudio: Integrated Development Environment for R. RStudio, Inc; 2018. Available at: http://www.rstudio.com/

58. $\mathrm{R}$ Core Team. A language and environment for statistical computing ( $R$ version 3.6.1). R Foundation for Statistical Computing, 2019. Available at: http://www.r-project.org/

59. Rosseel Y. lavaan: An R Package for Structural Equation Modeling. J Stat Softw 2012;48(2):1-36. https://doi.org/10.18637/jss.v048.i02 
60. Jorgensen TD, Pornprasertmanit S, Schoemann AM, Rosseel Y. semTools: Useful tools for structural equation modeling. $\mathrm{R}$ package version $0.5-1 ; 2018$. Available at: https://CRAN.R-project.org/package=semTools

61. Rizopoulos D. Itm: An R package for latent variable modelling and item response theory analyses. J Stat Softw 2006;17(5):1-25. https://doi.org/10.18637/jss.v017.i05

62. Kenny DA, Kaniskan B, McCoach DB. The Performance of RMSEA in Models with Small Degrees of Freedom. Sociol Methods Res 2015;44(3):486-507. https://doi.org/10.1177/ 0049124114543236

63. Taasoobshiraz G, Wang S. the performance of the srmr, rmsea, cfi, and tli: an examination of sample size, path size, and degrees of freedom. J Appl Quantitative Methods 2016;11(3):31-9.

64. Gouveia VV, Milfont TL, Da Fonseca PN, de Miranda Coelho JAP. Life satisfaction in Brazil: Testing the psychometric properties of the satisfaction with life scale (SWLS) in five Brazilian samples. Soc Indic Res 2009;90(2):267. https://doi.org/10.1007/s11205-008-9257-0
65. Pavot W, Diener E. Review of the Satisfaction with Life Scale. Psychol Assess 1993;5:164-71. https://doi.org/10.1037/1040-3590.5.2.164

66. McIntosh CN. Report on the construct validity of the Temporal Satisfaction with Life Scale. Soc Indic Res 2001;54:37-56. https://doi.org/10.1023/A:1007264829700

67. Lalor JP, Wu H, Yu H. Building an evaluation scale using item response theory. Proceedings of the Conference on Empirical Methods in Natural Language Processing. Conference on Empirical Methods in Natural Language Processing, 2016:648-657. https://doi.org/10.18653/v1/ d16-1062 PMid:28004039 PMCid:PMC5167538

68. Campbell DT, Russo MJ. Social measurement. Thousand Oaks: SAGE Publishing; 2001. https://doi.org/ 10.4135/9781412985857

69. Sánchez-Fuentes M, Santos-Iglesias P, Sierra JC. A systematic review of sexual satisfaction. Int J Clin Health Psychol 2014;14(1):67-75. https://doi.org/10.1016/S16972600(14)70038-9 


\title{
APPENDIX 1
}

Mais abaixo estão cinco afirmações sobre a sua vida sexual, com as quais pode concordar ou discordar. Utilizando a escala de 1 a 7 abaixo indicada, refira o seu grau de acordo com cada afirmação colocando o número apropriado na linha que precede cada um deles. Procure ser sincero(a) nas respostas que vai dar. Eis a escala de 7 pontos:

\author{
$1=$ Totalmente em desacordo \\ $2=$ Desacordo \\ $3=$ Ligeiramente em desacordo \\ $4=$ Nem de acordo nem em desacordo \\ $5=$ Ligeiramente de acordo \\ $6=$ Acordo \\ $7=$ Totalmente de acordo
}

1. Em muitos aspectos a minha vida sexual aproxima-se dos meus ideais.

2. As condições da minha vida sexual são excelentes.

3. Estou satisfeito(a) com a minha vida sexual.

4. Até agora consegui obter aquilo que era importante na vida sexual.

5. Se pudesse viver a minha vida sexual de novo, não mudaria quase nada.

$\begin{array}{lllllll}1 & 2 & 3 & 4 & 5 & 6 & 7 \\ 1 & 2 & 3 & 4 & 5 & 6 & 7 \\ 1 & 2 & 3 & 4 & 5 & 6 & 7 \\ 1 & 2 & 3 & 4 & 5 & 6 & 7 \\ 1 & 2 & 3 & 4 & 5 & 6 & 7\end{array}$

